\title{
The search for a civic commons online: an assessment of existing BBC Online policy
}

Ramsey, P. (2013). The search for a civic commons online: an assessment of existing BBC Online policy. Media, Culture and Society, 35(7), 864-879. https://doi.org/10.1177/0163443713495079

Link to publication record in Ulster University Research Portal

Published in:

Media, Culture and Society

Publication Status:

Published (in print/issue): 01/10/2013

DOI:

10.1177/0163443713495079

\section{Document Version}

Author Accepted version

\section{General rights}

Copyright for the publications made accessible via Ulster University's Research Portal is retained by the author(s) and / or other copyright owners and it is a condition of accessing these publications that users recognise and abide by the legal requirements associated with these rights.

\section{Take down policy}

The Research Portal is Ulster University's institutional repository that provides access to Ulster's research outputs. Every effort has been made to ensure that content in the Research Portal does not infringe any person's rights, or applicable UK laws. If you discover content in the Research Portal that you believe breaches copyright or violates any law, please contact pure-support@ulster.ac.uk. 
The search for a civic commons online: an assessment of existing BBC Online policy

Phil Ramsey, Ulster University

pt.ramsey@ulster.ac.uk

http://ulster.academia.edu/PhilRamsey | http://orcid.org/0000-0001-5873-489X

\title{
Published as:
}

Ramsey, P. (2013). The search for a civic commons online: an assessment of existing BBC Online policy. Media, Culture \& Society. 35(7), 864-879.

(http://dx.doi.org/10.1177/0163443713495079)

\begin{abstract}
Debates surrounding democracy and the Internet are of central importance to the future of public service broadcasting. Some of these debates have led a group of scholars to argue for the establishment of a civic commons online, in response to the commercial nature of the Internet and its limited support of deliberative democracy. General features of a civic commons online include the formation of a deliberative space free from corporate and state influence, yet that receives some form of public funding. Given their long and relatively successful history, some scholars have argued that existing public service broadcasters might provide the best chance for the establishment of such a commons. This article evaluates existing BBC Online policy in the UK in light of these arguments, and assesses the extent to which existing policy might allow space for the establishment of such a civic commons. The article concludes by arguing that while existing BBC Online policy would allow the basic grounds for the establishment of a civic commons online, there are significant obstacles to its full realisation.
\end{abstract}

Keywords: Public service broadcasting; digital democracy; Internet; civic commons; media policy; BBC Trust; BBC Online. 
The search for a civic commons online: an assessment of existing BBC Online policy

As the functioning of public spheres become increasingly linked to the Internet, there has been a wide-ranging body of work from a critical standpoint generated on their relationship (Dahlberg, 1998; 2001a; 2001b; Dahlgren, 2001; 2009; Downey \& Fenton, 2003; Moe, 2008; Roberts, 2009). While the Internet has promised and indeed delivered much in terms of its democratising potential, there remains a sizeable gap between utopian accounts of the Internet and democracy and empirical conditions (Curran, Fenton and Freedman, 2012). Foremost among reasons for this is that the Internet is primarily a commercial space organized along capitalist lines, rather than a civic space (Dahlgren, 2005; Hindman, 2009). In order to provide an alternative, a body of academic work has argued for the establishment of a 'civic commons' online, publicly funded, yet free from state influence (Bau, 2009; Blumler \& Coleman, 2001; Blumler and Gurevitch, 2001; Coleman, 2002; Coleman \& Blumler, 2009; Coleman \& Gøtze, 2001). The idea for such a civic commons is largely based on the model of public service broadcasting (PSB) that has been argued for as the corner stone of the public sphere (Curran, 1991; Garnham, 1986; Scannell, 1989). This article seeks to examine the arguments for a civic commons forwarded in this body of work, and to draw specific links to the BBC in the context of the UK. The article is a desk-based study that analyses BBC and BBC Trust policy documentation, alongside a range of web-based materials from the corporation. Following a survey of the main literature that relates to this area and an overview of the main theoretical positions on the subject, the article takes BBC Online as a case study (the Internet section of the UK's main public service broadcaster), and will assess the 
extent to which existing Internet policy at the BBC might allow for the establishment of a civic commons in the UK.

\section{Internet based democracy}

The relationship between democracy and the Internet has been approached by scholars from many intellectual traditions, including political science, legal studies and media and communication studies. Dahlgren (2005: 151) argues that Internet is a space largely colonized by corporations, and three key arguments flow from his work: first, that the Internet is increasingly becoming like the mass-media, where '...intensified commercialization' is standard; second, the potential of the Internet as a '...properly civic communicative space' is undermined, given the '...market logic' that underpins it and steers it in other directions (Dahlgren, 2005: 151); third, that political activity online is quite insignificant compared to other activities, where 'It is questionable if the public at present has any rights on the Net outside of their roles as capitalists or consumers' (Dahlgren, 2001: 49). Perhaps an example of this was the 2012 stock market flotation of Facebook, that reminded many that it was primarily a business entity run for the benefit of its investors, and not as a 'social service' in existence for the good of the public or to support notions of democracy online. Following a similar line of enquiry to Dahlgren, Hindman argues in The Myth of Digital Democracy (2009) that a series of false propositions govern how the Internet is generally thought of, as a democratising force for good. On this he argues, 'The Internet's success at democratizing politics are real. Yet the medium's failures in this regard are less acknowledged and ultimately just as profound' (Hindman, 2009: 4). Like Dahlgren, Hindman (2009: 4) suggests that a political-economy 
approach to the Internet shows it to be a space that is overwhelmingly dominated by narrow commercial interests, and as one that 'has fueled the creation of new political elites'. One of Hindman's areas of concern is to debunk the notion that because the Internet allows anyone to publish anything (within certain parameters) that this changes the nature of democracy. Rather he suggests that his research is '...careful to consider who speaks and who gets heard as two separate questions. On the Internet, the link between the two is weaker than it is in almost any other area of political life' (Hindman, 2009: 16--17). The Internet today is awash with content provided by millions of users, the majority of which goes unnoticed, or indeed is of a nature such that it contributes little to democracy online.

In a similar vein to Dahlgren and Hindman, Dahlberg (2001a) argues that the Internet is not an ideal provider of deliberative democratic ideals, and is rather colonized by state and corporate interests. By the normative measure of how the public sphere should operate from the work of Habermas $(1989,2009)$, the Internet fails to deliver a type of deliberatively democratic debate, and is instead dominated by corporate interests (Dahlberg, 2001a). Many 'single issue publics' operate within online spaces hosted by new media conglomerates (eg. the presence of a group or 'page' on Facebook that have become almost ubiquitous for sports groups, charities, fan clubs, and countless civil society organizations). Despite writing three years before the founding of Facebook, Dahlberg's (2001a: 617) description of '...the ongoing colonization of online life by economic interests' neatly describes the business model of the company. The Internet has been moulded to suit the consumer rather than the citizen, with Blumler and Gurevitch (2001: 8--9) arguing 'Few if any of these big players are likely to be out to boost 
citizenship'. Dahlberg (2001a: 622) suggests that '...media corporates are not the most suitable sponsors for democratic talk as their profit-making ambitions tend to inhibit rational-critical deliberation'. Where there is some cause for some optimism, it lies where the Internet underpins what Dahlberg calls the Deliberative Democracy Position (Dahlberg, 2011), as a theoretical category that can find its realisation in a range of settings online. This suggests that the Internet can expand the public sphere, based on the promotion of 'rational-critical' discourse (Habermas, 1997: 106). The discussion of the public sphere in light of the theory of deliberative democracy has featured elsewhere (Dahlgren, 2009; Haas, 1999; Habermas, 2009). However, realisations of deliberative democracy online remain limited, a situation that could be improved by giving public service broadcasters an expanded role in providing solutions.

Before moving to a survey of the more specific arguments for a civic commons online and the possible realization of it under PSB, it is at this point that comparisons between the Internet and PSB can be made, where PSB is theorized as a section of media that offers solutions to the failings of the Internet. This sets the context for the next section, where the potential role of PSB in the provision of a civic commons is explored. Iosifidis (2011: 619) argues that the Internet is limited to the extent that it can deliver the conditions required for democracy, and that ' $\ldots$ the democratizing and empowering functions of the Internet and the new social media is being exaggerated and represent technological optimism for a number of reasons'. He goes on to suggest that the Internet: can be 'chaotic' with regards to participation; that inclusiveness and censorship issues are weak points; is often 'partisan' in nature; and '...above all, extensive dialogue and critical discussion (the very essence of the public sphere) is often absent on the Net' 
(Iosifidis, 2011: 619). For Iosifidis, it is rather PSB that can fulfill much of these criteria. Where the Internet has been found to be lacking throughout its relatively short history, PSB has proven itself over many decades. While Iosifidis (2011: 628) does not think that PSB should remain unchanged -- rather it should adapt to the wider scope of "public service media' -- he does think that PSB incorporates many qualities that the Internet can as yet not match:

Apart from being universally accessible, PSB has proved a credible source of information; its trustworthiness is evidenced by the fact that most people turn to a PSB rather than to a commercial outlet whenever a major incident occurs in order to access independent reporting and find accurate and balanced information.

\section{Theories of the civic commons online and the role of Public Service Broadcasters}

The range of work that argues for the establishment of a civic commons online comes from a group of media and communications scholars whose writing draws on the work of the others, mainly connected by Stephen Coleman and Jay Blumler (Bau, 2009; Blumler \& Coleman, 2001; Blumler \& Gurevitch, 2001; Coleman, 2002; Coleman \& Blumler, 2009; Coleman \& Gøtze, 2001). It is important to note here that these publications have gained a wider audience than the academy, with an endorsement for the establishment of a civic commons online coming from UK thinktank the Institute for Public Policy 
Research (IPPR). The IPPR published two of the articles (Blumler \& Coleman, 2001; Coleman, 2002), while Coleman's proposals were reinforced in IPPR recommendations by Cowling and Tambini (2002). The arguments forwarded in these works argue for the development of civic engagement online, in a manner that is not often possible given the corporate domination of the Internet. They also suggest that the way that these online initiatives are designed will have an impact upon the outcome of the quality of the deliberation. Scholars have addressed the role that PSB may play in such a venture, and in supporting the public sphere more generally in a marketized new media environment (Coleman, 2002; Moe, 2008). One of the foundational arguments for a civic commons online comes from Dahlberg (2001a). He argues that there remains a '...need for public deliberations independent of administrative power', an argument which follows the classical Habermasian position that the public sphere should normatively exist outside of the control and reach of the state (Dahlberg, 2001a: 621). On this Dahlberg (2001a: 629) suggests that three solutions should be explored:

1. 'online spaces free from state and corporate power must be put aside for public deliberation';

2. 'financial support from government and non-government sources is desperately needed to develop these spaces; funding is required to enable deliberative initiatives to resist incorporation by commercial and non-deliberative interests and to expand, multiply and improve';

3. 'the efforts and energies of democracy advocates is needed to not only secure this regulatory and financial support but also to help with the development and 
improvement of deliberative spaces'.

On the second point, he cites Blumler and Gurevitch (2001), who draw on PSB models from the history of radio to argue for the creation of publicly funded deliberative forums that are independent of government. In the way that PSB radio has operated in the past and continues today, 'The corresponding challenge today is to fashion and apply a public service remit for the Internet and other online services' (Blumler and Gurevitch, 2001: 9).

In terms of the provision of such a civic commons, and of the development of deliberative democracy, Coleman (2002: 99) argues that rather than government being the provider -- 'Government is manifestly unable to create such a communication space' - PSB might be the sector to realize such potential. By contrast, Moe (2008) argues that PSBs can utilize the Internet as a means to disseminate information in addition to their broadcasting activities, in order to better claim that their activities underpin the public sphere. Compared with the criteria that Bernhard Peters sets out for the public sphere -that it must have 'equality and reciprocity' and 'openness and adequate capacity' (Moe, 2008: 323--324) -- Moe argues that PSB does not fulfill these, due to the fact that the speaker has much greater status than the audience. This follows in a tradition of suggesting that the public sphere and PSB cannot be analogous categories (Keane, 1995; Karppinen et al., 2008). Conversely, Curran (1991), Garnham (1986) and Scannell (1989) argue that PSB does fit with Habermas's account of the public sphere. PSB can also be said to fulfill necessary normative criteria for the underpinning of the public sphere, with regards to the principles of inclusion, deliberation and opinion formation (Ramsey, 2010a). Based on these arguments, PSB might be said to be a suitable provider of a civic commons online, and in addition, PSB encapsulates some of the other key principles for 
the establishment of a civic commons online as outlined above. PSB is formally independent from government, yet publicly funded, matching two key criteria. Moreover, its funding model allows it to operate in opposition to the logic of the market, another key requirement for a civic commons online. The next section will consider arguments that have a specific bearing on the suitability of the BBC to undertake such a role in the UK.

\section{The BBC as provider of the civic commons online}

It can be argued that the $\mathrm{BBC}$ has a range of qualities and a previous track record of activities that would make it suitable provider of the civic commons, either on a '...semiautonomous basis [...] or as an entirely new entity' (Blumler and Gurevitch, 2001: 9). Barnett (2006: 60) argues that despite accusations that the corporation leans to the right or to the left of the political spectrum (heard more loudly at different phases in its history), the $\mathrm{BBC}$ is perceived by most of the public as taking as 'fair, accurate and non-partisan'. He also notes that the $\mathrm{BBC}$ has been actively engaged in improving its role among a public who see politics as boring, to '...use the power of its reach and reputation to re-engage audiences' (Barnett, 2006: 60). To this end he cites several initiatives that the BBC became involved in, including a 2005 event to 'sustain citizenship' and the publication of the report Watching Alone: Social Capital and Public Service Broadcasting (Brookes, 2004) in conjunction with the Work Foundation. Along similar lines, Born (2006) comprehensively sketches academic and policy debates around democracy, PSB, the Internet and the public sphere, showing how the BBC began to use digital media to 'enhance' its services (at the level of the international; the nation; the regional; and the 
local). Here she offers four examples: first, a 2003 'Asylum Day', where the BBC's broadcast activities aligned with their online activities to highlight this area; second, the '...use of interactivity to enhance linear broadcast forms', where users could select their own version of radio drama The Dark Horse (Born, 2006: 110); the 2003 launch of iCan, which was designed to respond to lack of interest in politics (but has perhaps been superseded by the 2009 launch of Democracy Live); fourth, the case of BBC Hull Interactive, which for Born offered 'unprecedented levels of interactivity', and offered a mix of ICT training, education and local television news (Born, 2006: 110). For Born, the BBC's online activities have progressed to ensure that the corporation is significantly complementing its broadcast activities.

Perhaps the clearest argument for the BBC's delivery of a civic commons online comes from the work of Graham Murdock $(2004,2012)$. Murdock (2012) overviews the history of the concept of the commons, showing how it once again could be reclaimed under the $\mathrm{BBC}$. That the $\mathrm{BBC}$ might be the best placed institution to build a digital commons can be deduced for three reasons. On each, there is value in quoting Murdock (2012) at length:

1) '...[The $\mathrm{BBC}]$ can build on its pioneering role in presenting programmes not simply as events, to be listened to or viewed, but as points of entry into a range of related materials and opportunities for discussion and debate';

2) '...because of [the BBC's] continuing ability to command mass audiences it is best placed to develop collaborative projects that broaden access to the work of other public cultural institutions'; 
3) '...because [the $\mathrm{BBC}$ ] remains widely trusted and has built one of the best used web sites, it offers the optimum location for a general search engine enabling users to navigate their way around the cultural materials stored across all public institutions, not just in Britain but around the world'.

Murdock's three criteria build on a similar call some years previous when he forcefully argued for PSB to be reconceptualied as a '...principal node in an emerging network of public and civil initiatives that $[\ldots]$ provide the basis for new shared cultural space' (Murdock, 2004). As antidote to those scholars who uncritically accept the Internet as a commercial space, of which nothing can be done, Murdock's work offers a fresh vision for the future of the BBC. In the next section, this article will turn to examine existing $\mathrm{BBC}$ Online policy, and to assess the extent to which existing policy might allow space for the establishment of a civic commons in the UK.

\section{Existing BBC Online Policy}

The $\mathrm{BBC}$ is the UK's main public service broadcaster, having been incorporated by Royal Charter in the UK in 1926 (that has been extended periodically every ten years since, with the last being granted in 2006). Constitutionally, the BBC is afforded independence from the state within the parameters of the charter, in particular with relation to its content: 'The $\mathrm{BBC}$ shall be independent in all matters concerning the content of its output, the times and manner in which this is supplied, and in the management of its affairs' (BBC, 2006). It is this constitutional independence that affords 
the BBC its very legitimacy. Publicly funded (though distinct from UK fiscal policy), the corporation stands as one of the leading examples of PSB around the world. The BBC -despite its detractors from some areas of politics and business -- is extremely well respected across ideological, national and economic divides. Within the wider organisation that is dominated by its television and radio output, $\mathrm{BBC}$ Online is expected to 'promote the BBC's public purposes' (discussed below), by 'providing innovative and distinctive online content and distinctive propositions that reflect and extend the range of the BBC's broadcast services' (BBC Trust, 2012a: 1). Accordingly BBC Online exists across a wide range of websites and mobile Internet based services, with BBC News (www.bbc.co.uk/news), BBC Sport (www.bbc.co.uk/sport) and the BBC iPlayer (www.bbc.co.uk/iplayer) making up the largest share of the Internet presence that the corporation has in the UK. In terms of funding, the BBC Online budget in 2012-13 was $£ 109.1$ million, representing only a very small percentage of the overall licence fee income (5 per cent of the licence fee is spent on BBC Online each month) (BBC Trust, 2012b).

The central policy document that outlines existing $\mathrm{BBC}$ online policy is the $\mathrm{BBC}$ Online Service Licence (May 2012), in which the BBC Trust set out the parameters for the BBC's Internet services (1). The core remit statement that BBC Online must 'promote the BBC's public purposes' is given additional context through three controlling principles:

1. BBC Online should afford users 'greater choice and control', especially though the provision of on-demand content. This is primarily delivered by the BBC 
iPlayer, a 'catchup' service, available on the Internet, on mobile devices and through various television satellite and cable providers (BBC Trust, 2012a: 1).

2. A 'deeper relationship' with the licence fee payer should result from BBC Online services, and accountability to the public should also be strengthened through online provision (BBC Trust, 2012a: 1). As such, BBC Online should afford the corporation opportunities to publish information on its activities and economic performance, and engage with the audience (eg. through email and social media; Twitter is used extensively to complement BBC broadcasting).

3. The creation of 'public value' must be tempered by the avoidance of 'negative market impact' (BBC Trust, 2012a: 1). Thus, BBC Online must at all times be taking account of the impact its online activities are having on competitors. Key competitors include Mail Online, the online version of UK newspaper the Daily Mail, which is the newspaper website with the most visits in the UK and the world (Greenslade, 2012).

On points one and two, these principles show that the $\mathrm{BBC}$ is perhaps beginning to consider its online audience in separate terms. In offering 'greater choice and control' online than to 'broadcast-only' viewers and listeners, the BBC hints at the presence of a two-speed audience, where those with an Internet connection can receive more extensive $\mathrm{BBC}$ services than those without. For the $\mathrm{BBC}$ to move in this direction seems to undermine the basis of the licence fee. The payment of the TV licence fee leads one to 
expect to receive the same service as all other licence fee holders. Indeed, this undermining of the licence fee is somewhat institutionalized in the policy on the BBC iPlayer (the corporation's 'catch-up' TV service). While broadcast viewers are obliged to pay the TV licence fee (avoidance can result in prosecution and a fine), online-only users can avoid paying the licence fee as long as they do not watch programming as it is being simultaneously broadcast on television and radio (BBC, 2012a). However, online viewers are not tracked and prosecuted by a dedicated organisation in the way that errant television viewers without a licence are. In 2011 the BBC admitted that it did not have the tracking technology to catch TV licence evaders who watch television only through the BBC iPlayer (Barnett, 2011), though rather contradictorily it has stated elsewhere that 'It forms part of our normal enforcement operation and TV Licensing has caught evaders watching television online' (BBC, 2010a). This unclear position is unfortunate for two reasons. Firstly, the House of Lords, Select Committee on Communications suggested in July 2012 that in the future all television in the UK may be delivered over broadband (to free up radio frequency spectrums for mobile phones), and this would tend to fit with current technological changes. Secondly, the BBC (2012b) advertises on one of its own websites that the iPlayer can be delivered directly to television sets through YouView, 'smart TVs' and other devices connected to the Internet. Given both of these, it seems that the TV licence fee could be rendered redundant within a few years, bizarrely undermined by the $\mathrm{BBC}$ itself. As a result the $\mathrm{BBC}$ must ensure that adherence to the licence fee is fairly monitored, giving equal resources to those who watch television through television sets and those who watch online. However, if the user only uses iPlayer as a 'catch-up' only service, they do not need to pay the licence fee. The BBC 
must give careful consideration to the implications of this for the continuance of its revenue stream. Much work needs done at the media policy level in the UK, involving the Department for Culture, Media and Sport and Ofcom, in order to forge a way ahead.

On point three, the BBC's Internet services are carefully scrutinized by commercial rivals, due to the concerns that the BBC's online presence will dent the commercial activities of rivals. The $\mathrm{BBC}$ is governed on the matter by four policy documents: Statement of Policy on Fair Trading; Statement of Policy on Competitive Impact; Competitive Impact Framework Competitive; Impact Code on Cross-Promotion (BBC Trust, 2009: 5). These policies are 'designed to minimise, as far as possible whilst always ensuring the fulfilment of the Public Purposes and other obligations, the BBC's potential for creating negative impacts on the markets in which it operates' (BBC Trust, 2009: 2). The licence fee income of $£ 3.606$ bn in 2012 , that is raised from every household in the UK with a television set, represents a very large income that is separate to commercial activity in the UK media market (BBC, 2012c) (2). The BBC exists under continual pressure from the market to not infringe too far, and often acts on its demands. The February 2010 decision to postpone the launch of the BBC's iPhone applications followed pressure from the Newspaper Publishers Association. The decision was a fairly clear-cut example of the $\mathrm{BBC}$ acquiescing to the pressure from the market in terms that were fairly blatant, as at the time most other UK news organisations had a mobile application available for download, and mobile applications were by that point seen as an essential part of news delivery (Ramsey, 2010b). While the BBC later reversed its decision, it was an important moment in the relationship between the corporation and the media market in the development of the digitisation of PSB, and in the move from PSB to 
public service media.

\section{BBC Online and the relationship with the corporation's 'Public Purposes'}

The BBC is governed by six public purposes that it must abide by, as set out in the BBC Agreement. This is a supplementary document to the Royal Charter, and is one that elaborates on its terms. It states that the BBC should be held to account to its 'public purposes', not by government, but by the BBC Trust (DCMS, 2006: i). The six purposes are: 'Bringing the World to the UK and the UK to the World'; 'Sustaining citizenship and civil society'; 'Emerging Communications'; 'Stimulating Creativity and Cultural Excellence'; 'Promoting Educating and Learning'; 'Representing the UK, its nations, regions and communities'. This section will address one of the six BBC public purposes -- Sustaining citizenship and civil society -- as it perhaps fits best with the idea of the civic commons online. To achieve the purpose of Sustaining citizenship and civil society, the $\mathrm{BBC}$ sets out to do five things across all its media, that are comprised of television, radio and Internet: 'Provide independent journalism of the highest quality'; 'Engage a wide audience in news, current affairs and other topical issues'; 'Encourage conversation and debate about news, current affairs and topical issues'; 'Build greater understanding of the parliamentary process and political institutions governing the UK'; 'Enable audiences to access, understand and interact with different types of media' (BBC Trust, 2007: 1). Under the terms of 'encouraging conversation', the BBC Trust $(2007: 1)$ note that 'BBC news and current affairs should inform conversation and debate among friends, family and wider groups through forums for debate such as phone-ins and online discussion 
areas'. Thus the BBC is already thinking in deliberative terms, and using the language of deliberative democracy. The move to the formal establishment of a civic commons would be wholly in line with the Sustaining citizenship and civil society public purpose, and take the corporation closer towards meeting its goals in this area.

In the deliberative public sphere, information and news is a crucial to rational-critical debate, which gives rise to public opinion. For Habermas this is distinct from what he terms 'mere opinions', which are private and without scrutiny (1997: 106). Indeed, the BBC Trust (2007: 9) come close to using this type of language when describing the importance of reliable information in the public sphere, when it states: 'The Trust sees a clear role for the $\mathrm{BBC}$ in providing accurate information to enable people to take part in the debates that sustain the democratic process and civil society'. In terms of how BBC Online attempts to bring about these conditions, it is charged with making 'a very important contribution to this purpose amongst its users, primarily by providing comprehensive and constantly updated, accurate, impartial and independent news which aims to engage a broad audience in news and current affairs' (BBC Trust, 2012a: 4). Thus, BBC Online must produce news content that comes up to the same journalistic standards as that of its television and radio operations. In the same respect that $\mathrm{BBC}$ radio and television aim to 'stimulate' their audiences to response (and through a plethora of write-in and phone-in discussion-based programming), BBC Online is required to 'aim to encourage conversation and debate about news, current affairs and topical issues, both online and more broadly. It should offer specific resources which help to build users' understanding of the UK's political institutions and democratic processes' (BBC Trust, 2012a: 4). Like the overall activities of the BBC, BBC Online is specifically tasked with 
bringing about conditions that could only be enhanced by the establishment of a civic commons online. Rather than being at odds with one of the requirements that BBC Online must fulfill, a civic commons online would strengthen the corporation with regards to what the $\mathrm{BBC}$ Trust requires.

\section{Interacting with the audience}

In its support of the public purposes, existing BBC Online policy suggests that the corporation 'may host user-generated content, particularly material which helps contribute to the promotion of the public purposes by encouraging active audience involvement, including participation in online discussion of important issues' (BBC Trust, 2012a: 2). Returning to the public purpose Sustaining citizenship and civil society (to 'aim to encourage conversation and debate'), BBC Online has across the last decade significantly used user-generated content (UGC) as a means of interacting with the audience, and of encouraging the citizenry to take an active interest in the generation of news and content: 'The spread of citizen-journalism, blogging and other user-generated content, demonstrates an increasing interest within the audience for direct and active engagement with the news and its underlying issues' (BBC Trust, 2007: 9). To this end the audience are asked to submit stories, photographs and videos that may be newsworthy. A primary method for this is through the Have Your Say service, that enables users to comment on stories (BBC, 2010b). User comments are placed on the same page as the news story written by the professional journalist, albeit at the bottom of the page and in a more conspicuous position. This service might be used for debate 
between participants, though it is not set up in a forum style, and can be said to have limited value in terms of sustaining any notion of deliberation that would feed into a version of online deliberative democracy.

While it intends to continue to incorporate UGC, one senior figure at the BBC has suggested that UGC is subservient to, not equal to professional journalism. Horrocks (2008) noted: 'The wider range of sources generated by audiences should improve our story gathering and the quality of what we do, but I believe that still needs to be assessed and delivered through an expert journalistic prism - at least for an organization with the particular responsibilities incumbent on the BBC'. The BBC seems to want to integrate UGC, but within certain parameters. As things stand, there appears to be no move at the corporation to full democratisation of content. Rather, professional journalism will remain the main source of news for the foreseeable future. This approach tends to be confirmed by Wahl-Jorgensen et al. (2010: 190), who cast doubt on the efficacy of UGC, given the 'lack of interest in, and respect for, audience comment'. Seeking to tie a discussion of it to the theory of the public sphere, they argue much of UGC is at odds with public sphere principles: 'the valourization of the emotional response caused by audience content runs counter to ideals of dispassionate rationality in the public sphere. It cautions us to consider whether we should celebrate the expression and elicitation of emotion in its own right, or whether we should consider the political consequences of emotional over rational engagement and participation' (Wahl-Jorgensen et al., 2010: 190). There is however a difference between the replacement or the undermining of professional journalism, and the integration of UGC into news. While UGC may never reach journalistic standards that public spheres require to function correctly, the 
integration of users into a civic commons online is another matter. Indeed it can be argued that for a civic commons online to function properly, interlocutors need information of a quality that allows them to form rational opinions. Thus UGC should in no way replace or perhaps even be used to compete with professional journalism at the BBC. In a paper written for the BBC, Coyle (2012) argues that mass media continue to sit at the centre of the democratic process: equipping citizens with the information they need to play a full role in civic life; equipping interlocutors with the basis for argumentation required in the properly functioning public sphere. Coyle (2012: 117) suggests:

All public services are important to their users. However, the media have an additional dimension of importance which stems from their role in citizenship and civic life. In addition to their indirect impact through shaping our collective experience, they offer the most frequent means by which voters can become aware of issues of accountability in the political process, as well as potentially influencing voters' choices in elections.

A civic commons built around the kind of journalism that the $\mathrm{BBC}$ offers could provide a substantial platform for online deliberation that is tied to quality journalism. The BBC has the structures in place that could provide this kind of service. However, the next section will discuss some of the remaining obstacles to the establishment of a civic commons online at the BBC. 


\section{Conclusion: can BBC Online provide a solution in the search for a civic commons?}

Existing BBC Online policy offers opportunities for the establishment of a civic commons online, and there are ways in which the establishment of such a commons would contribute to the $\mathrm{BBC}$ meeting the $\mathrm{BBC}$ Trust's requirements for what $\mathrm{BBC}$ Online should deliver. Regarding the public purpose Sustaining citizenship and civil society, the establishment of a civic commons online would directly benefit the corporation in its need to meet conditions laid out by the BBC Trust. Returning to the 'three controlling principles' set out above, a civic commons online would afford users 'greater choice and control', to the extent that the provision of on-demand content through the iPlayer could be complemented by opportunities to engage in deliberative debate. For example, the iPlayer website currently does not have forums where viewers can comment on programmes; the addition of such a feature would enable viewers more information on the contents of a programme, and show how programmes are being perceived by other viewers. Simply farming this role out to social media platforms like Twitter would involve the BBC abdicating on some of its responsibilities, as it is coming close to doing. Furthermore, the 'deeper relationship' with licence fee payers that should result from BBC Online services, and improved BBC accountability to the public, could both realistically be strengthened by the establishment of civic commons online. Indeed the civic commons online established by the $\mathrm{BBC}$ could act as a forum for the public to discuss the $\mathrm{BBC}$ and act as a conduit for public opinion to the BBC Trust. While there are some opportunities for the establishment of a civic commons online within existing BBC Online policy, there are also extant obstacles to the full establishment of such a service.

Firstly, the BBC's online activities are at present subjugated to the demands of the 
market and are constant scrutiny from commercial rivals. While the mere existence of $\mathrm{BBC}$ Online is an affront to many market fundamentalists where media provision is concerned, the argument for further expansion -- such as in the case of the establishment of a civic commons online -- would be difficult for the BBC to make. For example, Michalis (2012) comprehensively outlines the extent to which commercial pressure can be brought to bear upon the online activities of the $\mathrm{BBC}$, seen foremost in the case of BBC Digital Curriculum. The closure of the service in 2008 shortly after its launch, was for Michalis (2012: 956) particularly ' ... intriguing because it concerns education, a core PSB mission'. Surely proposals for a BBC civic commons would receive similar pressure? If a civic commons online is supposed to be free from the market, then the organisation that establishes it needs freedom from the market ensured. Under current rules this is not the case, as the BBC must avoid '...negative market impact' (BBC Trust, 2009: 2). However, the creation of a civic commons online may well involve the creation of negative market impact, leading to the likelihood of one being established small. One of the specific arguments for the establishment of such a commons -- that a space free from commercial interests may be established -- might be the very reason for blocking its realization. Indeed, this is to say nothing of the financial cost that setting up the civic commons online would have attached to it. As noted above, only 5 per cent of the monthly licence fee is currently spent on BBC Online. Finding additional funding at the corporation for a venture of this scale might be quite difficult, especially at a time when the Delivering Quality First cost cutting measures are still being implemented. Outside of the impact on the market, the prospect of a major investment in the expansion of $\mathrm{BBC}$ Online in such a funding climate might alone be reason why such an online civic 
commons would not be established.

Secondly, the establishment of a civic commons online would further entrench a 'twospeed' audience for the BBC, whereby those with Internet access would receive an enhanced service as compared to those without. While this is arguably already the case (those who can access the $\mathrm{BBC}$ online already have many additional services), the establishment of such a service would increase this divide. Under the terms of the current licence fee arrangement, those members of the audience paying their annual licence fee subscription should reasonably expect access to all services. Rather, a civic commons online, established as a major new BBC service, would exclude many. Perhaps Internetenabled television sets (the aforementioned Smart TV) offer some solution, but until Internet access at home is as widespread as that of television and radio (delivered digitally), this remains untenable. In 2012, while 80 per cent of households in Great Britain (excluding Northern Ireland) had Internet access, the remaining 20 per cent totals 5.2 million households in Great Britain (ONS, 2012). While possession of a TV licence remains a legal requirement for accessing the BBC's broadcast services, offering a significantly lesser service to 20 per cent of the population would be untenable. Moreover, it would doubtless face a challenge from the BBC Trust and relevant Parliamentary committees on these grounds. Were an online civic commons to be established, predicting the extent of the take-up of the service would be difficult. The $\mathrm{BBC}$ would need to carry out extensive research on this matter, by surveying licence fee payers as to the levels of demand that might be expected, and the kinds of features that users would particularly like to see included. A period where a pilot version is made available to testers would need to ensue. Such research would show the expected 
percentage of licence fee payers who might use an online civic commons, and it is in this period that the BBC would need to establish the lower levels of usage that it would find acceptable. However, predicted lows levels of take-up as compared to other BBC services, need not in and of itself prevent the service being established. Many of the BBC's existing services are used by low numbers of licence fee payers and yet are retained for the way in which they help deliver on the BBC's public purposes (eg. BBC Parliament).

Thirdly, existing BBC Online policy currently complements the BBC's television and radio output on the public purpose Sustaining citizenship and civil society, a principle that separates the corporation from most market provided media in the UK. However, current services such as the integration of UGC and Have Your Say are limited in their efficacy with regards to the development of deliberative democracy online. The establishment of a civic commons online would require the BBC to include services that are more deliberative in their nature. However, how the corporation sets the rules for engagement would doubtless be up for debate. The BBC currently has a set of 'house rules' that govern users postings (BBC, 2013), while the Guardian's Community standards and participation guidelines may act as another example to follow in practice (Guardian, 2009). Dahlberg's (2001a) six-fold model online deliberation may act as an example of an important theoretical framework (3). In order to answer the charge from Wahl-Jorgensen et al. (2010) on the efficacy of UGC in the public sphere, there would need to remain a formal separation between professional journalism and the activity of the civic commons online. However, designing services that would take a BBC civic commons online beyond the "valourization of the emotional response caused by audience 
content' (Wahl-Jorgensen at al., 2010: 190) would be perpetually difficult. Interesting and effective solutions would need to be considered by journalists, academics, cultural policy makers and legal professionals, in order to surmount difficulties that come in the attempt to establish the principles of deliberative democracy online. In the UK, the BBC offers what is perhaps the best chance for the establishment of a civic commons online, a service which might further enhance the role of the media in a democratic society. As has been set out, an assessment of existing BBC Online policy shows that in part the grounds for the establishment of a civic commons online are in place, but significant obstacles remain to the establishment of a civic commons online. These obstacles, and the fact that the likelihood that such a service will be established is small, do not however undermine the importance of a discussion on the theory of the civic commons online, and the chance to consider solutions that might improve the quality of deliberation within the public sphere. 



\section{Notes}

(1) The BBC Trust sets the overall strategic direction for the $\mathrm{BBC}$, while the $\mathrm{BBC}$ Executive carry out the day-to-day running.

(2) The BBC's total income in 2012 of $£ 5.086$ bn (a figure that includes commercial activities) makes it the second largest media institution in the UK after BSkyB (with revenue of $£ 6.6$ bn) (BBC, 2012c).

(3) Dalhberg's six principles participants for online deliberation are: Exchange and critique of reasoned moral-practical validity claims; reflexivity; ideal role taking; sincerity; discursive inclusion and equality; autonomy from state and economic power (Dalhberg, 2001a: 623). 


\section{References}

Barnett E (2011) BBC 'won't pursue iPad TV licence cheats'. Daily Telegraph. Available at: http://www.telegraph.co.uk/technology/news/8313770/BBC-wont-pursue-iPad-TVlicence-cheats.html (accessed July 2012).

Barnett S (2006) Can the BBC Invigorate our Political Culture? In: Lloyd, J and Seaton, J (eds) What Can Be Done? Making the Media and Politics Better. Oxford: Blackwell, pp.58--69.

Bau A (2009) Realising Online Democracy: A Critical Appraisal of "Online Civic Commons". Compass Thinkpieces. Available at: http://

clients.squareeye.com/uploads/compass/documents/CTP51BauDemocracy.pdf (accessed December 2010).

BBC (2006) Royal Charter. London: BBC.

BBC (2010a) TV Licence Fee: briefing. BBC. Available at:

http://www.bbc.co.uk/pressoffice/keyfacts/stories/licencefee2.shtml (accessed July 2012).

BBC (2010b) Have Your Say. BBC. Available at:

http://www.bbc.co.uk/news/have_your_say/ (accessed December 2010).

BBC (2012a) Do I need a TV licence to watch programmes on BBC iPlayer? BBC. Available at: http://iplayerhelp.external.bbc.co.uk/help/playing_tv_progs/tvlicence/ (accessed July 2012).

BBC (2012b) Where to get BBC iPlayer. BBC. Available at: http://iplayerhelp.external.bbc.co.uk/help/where_to_get_iplayer/television/ (accessed August 2012).

BBC (2012c) Full Financial Statements, 2011/12. London: BBC.

BBC (2013) House Rules. BBC. Available at:

http://www.bbc.co.uk/blogs/moderation.shtmllhhouse (accessed January 2013).

BBC Trust (2007) BBC Public Purpose Remit: Sustaining citizenship and civil society. London: BBC Trust.

BBC Trust (2009) Review of Fair Trading Policies. London: BBC Trust.

BBC Trust (2012a) BBC Online Service Licence. Issued May 2012. London: BBC Trust.

BBC Trust (2012b) The BBC's year, 2011-2012. London: BBC Trust. 
Blumler JG and Coleman S (2001) Realising Democracy Online: A Civic Commons in Cyberspace. IPPR/Citizens Online Research Publication, No.2. London: IPPR.

Blumler JG and Gurevitch M (2001) The New Media and our Political Communication Discontents: democratizing cyberspace. Information, Communication \& Society 4(1): 1-13.

Born, G (2006) Digitising Democracy. In: Lloyd, J and Seaton, J (eds) What Can Be Done? Making the Media and Politics Better, Oxford: Blackwell, pp.102--123.

Brookes, M (2004) Watching alone: Social capital and public service broadcasting. London: The Work Foundation/ BBC.

Coleman S (2002) From service to Commons: re-inventing a space for public communication. In: Tambini, D and Cowling, J (eds) From public service broadcasting to public service communications. London: IPPR, pp.88--98.

Coleman S and Blumler J (2009) The Internet and Democratic Citizenship. Cambridge: Cambridge University Press.

Coleman S and Gøtze J (2001) Bowling Together: Online Public Engagement in Policy Deliberation. London: Hansard Society.

Cowling J and Tambini D (2002) Conclusions and recommendations. In: Tambini, D and Cowling, J (eds) From public service broadcasting to public service communications. London: IPPR, pp.171--181.

Coyle D (2012) Public Value in Practice: Restoring the ethos of public service. London: BBC Trust.

Curran J (1991) Rethinking the Media as a Public Sphere. In: Dahlgreen, P and Sparks, C (eds) Communication and Citizenship: Journalism and the Public Sphere in the New Media Age. London: Routledge, pp.27--57.

Curran J, Fenton N and Freedman D (2012) Misunderstanding the Internet. Oxon: Routledge.

Dahlberg, L (1998) Cyberspace and the Public Sphere: Exploring the Democratic Potential of the Net. Convergence 4(1): 71--84.

Dahlberg L (2001a) The Internet and Democratic Discourse: Exploring the prospects of online deliberative forums extending the public sphere. Information, Communication \& Society 4(4): 615--633.

Dahlberg L (2001b) Computer-Mediated Communication and The Public Sphere: A 
Critical Analysis. Journal of Computer-Mediated Communication 7(1): 1--22.

Dahlberg L (2011) Re-constructing digital democracy: An outline of four 'positions'. New Media \& Society 13(6): 855--872.

Dahlgren P (2001) The Public Sphere and the Net: Structure, Space and Communication. In: Lance Bennett, $\mathrm{W}$ and Entman, R (eds) Mediated Politics: Communication in the Future of Democracy (Communication, Society and Politics).Cambridge: Cambridge University Press, pp.33--55.

Dahlgren P (2005) The Internet, Public Spheres, and Political Communication: Dispersion and Deliberation. Political Communication 22(2): 147--162.

Dahlgren P (2009) Media and Political Engagement: citizens, communication and democracy. Cambridge: Cambridge University Press.

DCMS (2006) Broadcasting: An Agreement Between Her Majesty's Secretary of State for Culture, Media and Sport and the British Broadcasting Corporation. London: HMSO.

Downey J and Fenton N (2003) New media, counter publicity and the public sphere. New Media \& Society 5(2): 185--202.

Garnham N (1986) Media and the public sphere. In: Golding, P, Murdock, G and Schlesinger, P (eds) Communicating Politics. Leicester: Leicester University Press, pp.37--53.

Greenslade R (2012) Mail Online goes top of the world. Daily Mail. Available at: http://www.guardian.co.uk/media/greenslade/2012/jan/25/dailymail-internet (accessed January 2013).

Guardian (2009) Community standards and participation guidelines. Guardian. Available at: http://www.guardian.co.uk/community-standards (accessed January 2013).

Haas T (1999) What's "Public" about Public Journalism? Public Journalism and the Lack of a Coherent Public Philosophy. Communication Theory 9(3): 346--364.

Habermas J (1989) Structural Transformation of the Public Sphere. Cambridge: Polity.

Habermas J (1997) The Public Sphere. In: Goodin, R and Pettit, P

(eds) Contemporary Political Philosophy. Oxford: Blackwell, pp.105--108.

Habermas J (2009) Europe: The Faltering Project. Cambridge: Polity.

Hindman M (2009) The Myth of Digital Democracy. Princeton: Princeton University Press. 
Horrocks P (2008) The value of Citizen Journalism. BBC. Retrieved from http://www.bbc.co.uk/blogs/theeditors/2008/01/value_of_citizen_journalism.html (accessed September 2009).

Iosifidis P (2011) The Public Sphere, Social Networks and Public Service Media. Information, Communication \& Society 14(5): 619--637.

Karppinen K, Moe H and Svensson J (2008) Habermas, Mouffe and Political Communication. Javnost/The Public 15(3): 5-22.

Keane J (1995) Structural transformations of the public sphere.

Communication Review 1:1--22.

Michalis M (2012) Balancing public and private interests in online media: the case of BBC Digital Curriculum. Media, Culture \& Society 34(8): 944--960.

Moe H (2008) Dissemination and dialogue in the public sphere: a case for public service media online. Media, Culture \& Society 30(3): 319--336.

Murdock G (2004) Building the Digital Commons: Public Broadcasting in the Age of the Internet. University of Montreal, The 2004 Spry Memorial Lecture, Vancouver, 18 November 2004/ Montreal, 22 November 2004.

Murdock G (2012) A tale of two charters: the BBC and the commons. OpenDemocracy. Available at: http://www.opendemocracy.net/ourbeeb/graham-murdock/tale-of-twocharters-bbc-and-commons (accessed November 2012).

ONS (2012) Internet Access - Households and Individuals, 2012. Available at: http://www.ons.gov.uk/ons/dcp171778_275775.pdf (accessed January 2013).

Ramsey P (2010a) Public Service Broadcasting and the Public Sphere: Normative Arguments from Habermasian Theory. Networking Knowledge: Journal of the MeCCSA Postgraduate Network 3(2): 1--14.

Ramsey P (2010b) Response to BBC Strategy Review 2010. Centre for Media Research, Media Policy Briefing Paper No.6. Coleraine: University of Ulster.

Roberts B (2009) Beyond the "Networked Public Sphere": Politics, Participation and Technics in Web 2.0. Fibreculture 14.

Scannell P (1989) Public service broadcasting and modern public life. Media, Culture \& Society 11: 135--166. 
Wahl-Jorgensen K, Williams A and Wardle C (2010) Audience Views on UserGenerated Content: Exploring the value of news from the bottom up. Northern Lights 8: 177--194. 